\title{
Adult Cholangiocarcinoma
}

National Cancer Institute

\section{Source}

National Cancer Institute. Adult Cholangiocarcinoma. NCI Thesaurus. Code C8265.

A cholangiocarcinoma occurring in adults. 